\title{
Manejo do dinheiro e qualidade conjugal
}

\author{
Jeniffer Harth
}

Denise Falcke

\section{RESUMO}

A qualidade conjugal é influenciada por diversos fatores, dentre eles, o dinheiro. Sendo assim, objetivou-se investigar a relação entre o manejo do dinheiro e a qualidade conjugal. Realizouse uma pesquisa quantitativa com delineamento correlacional. Participaram 143 casais, casados oficialmente ou morando juntos, entre 19 e 81 anos. Aplicou-se um questionário sociodemográfico, a DAS, o GRIMS e um questionário sobre manejo do dinheiro. Foram feitas análises descritivas e inferenciais. Os resultados revelaram que a maioria dos casais $(58 \%)$ utiliza o sistema de gestão compartilhada do dinheiro, enquanto que $25 \%$ manejam separadamente e $17 \%$ delegam a um dos cônjuges o manejo. Os casais que compartilham o manejo financeiro obtiveram maiores níveis de qualidade conjugal e maior grau de felicidade com o relacionamento. Esses resultados corroboram com estudos anteriores, confirmando que o manejo do dinheiro está associado com a qualidade conjugal.

Palavras-chaves: dinheiro; qualidade conjugal; finanças; casamento.

\section{ABSTRACT}

\section{Management of money and marital quality}

Marital quality is influenced by several factors, among them, money. Therefore, this study aimed to investigate the relationship between money management and marital quality. We performed a quantitative research with a correlational design. One hundred and forty-three couples, officially married or living together, between 19 and 81 years participated. We applied a sociodemographic questionnaire, the DAS, the GRIMS and a questionnaire about handling money. Descriptive and inferential analysis were made. The results revealed that the majority of couples (58\%) uses the shared management system of money, $25 \%$ manage separately and $17 \%$ delegate the management to one of the spouses. The couples who uses the shared management showed higher levels of marital quality and greater degree of happiness with the relationship. These results corroborate previous studies, confirming that the management of money is associated with marital quality

Keywords: money; marital quality; finances; marriage.

A vida a dois movimenta-se por distintas experiências que são, ao mesmo tempo, a causa e o resultado da relação, como apoio mútuo, humor, comunicação, diálogo, carinho, opiniões, acordos, críticas, conflitos, conforto nas dificuldades e vivência de ambivalências. Além de todas essas experiências, para uma relação conjugal ser plena, é preciso que o casal tenha disposição em ceder e isso significa, muitas vezes, abrir mão do controle em favor da relação (Silveira, 2007). Na dinâmica do casal, não se pode esquecer que a relação conjugal envolve a individualidade de cada parceiro e a conjugalidade que esse casal irá construir com a relação (Féres-Carneiro, 1998), sendo que a individualidade se refere à identidade de cada um, enquanto que a conjugalidade se refere à sua vivência conjunta (Magalhães, 2003). Ainda assim, é importante lembrar que, em uma relação conjugal, existem os limites de um e do outro e é aprendendo a lidar com esses limites que o casal construirá uma vida compartilhada e poderá melhor vivenciar a qualidade conjugal (Whitaker, 1990).

O conceito de qualidade conjugal é um tanto subjetivo, pois não se pode afirmar o que

\section{Sobre os Autores}

J.H.

orcid.org/0000-0001-6983-1978 Universidade do Vale do Rio dos Sinos (UNISINOS) - São Leopoldo

jeni.psico@yahoo.com.br

D.F.

orcid.org/0000-0002-4663-1216 Universidade do Vale do Rio dos Sinos (UNISINOS) - São

Leopoldo

dfalcke@unisinos.br

\section{Direitos Autorais}

Este é um artigo de acesso aberto e pode ser reproduzido livremente, distribuído, transmitido ou modificado, por qualquer pessoa desde que usado sem fins comerciais. 0 trabalho é disponibilizado sob a licença Creative Commons CCBY-NC.

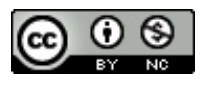




\section{INTERACÃO EM LF PSICOLOGIA}

exatamente a define em um ou outro casal, mas sabe-se que é resultado de um processo dinâmico, interativo e singular. A qualidade conjugal é multifatorial, sendo que as principais dimensões que envolvem esse conceito são: o contexto, os recursos pessoais dos cônjuges e os seus processos adaptativos (Mosmann, Wagner, \& Féres-Carneiro, 2006). Com essas, a qualidade conjugal é atravessada e influenciada por todas as variáveis que a compõem, como o tempo de casamento (VanLaningham, Johnson, \& Amato, 2001), atitudes, valores, sexo, presença ou não de filhos, nível de escolaridade, cultura, trabalho, nível socioeconômico dos cônjuges (Sharlin, Kaslow, \& Hammerschmidt, 2000), experiências na família de origem e características de personalidade (Mosmann et al., 2006). Estudos longitudinais internacionais evidenciam que as pessoas que se casam, permanecem no casamento e têm filhos geralmente são aquelas que possuem maior nível educacional e melhores perspectivas econômicas (Carlson, McLanahan, \& England, 2004; Sweeney, 2002).

É esperado que em um relacionamento haja intimidade, afeto, realização sexual e mesmo amizade (Ricotta, 2002), mas, com o passar do tempo, o dinheiro pode tornar-se imprescindível, inclusive, para que os cônjuges possam manter os custos dos programas que gostam de fazer juntos. As questões financeiras de um casal dificilmente são um assunto conversado entre os cônjuges no início de uma relação, pois, nessa etapa, não há a preocupação do quanto cada um será responsável na obtenção e divisão do dinheiro na relação conjugal (Teykal \& Rocha-Coutinho, 2007). Entretanto, na relação cotidiana do casal, já não mais no início desta, costuma haver uma reivindicação por divisão de tarefas que sejam justas, em que os cônjuges se responsabilizem pelos compromissos da relação de forma igualitária. Essa reivindicação também tem ocorrido no que diz respeito às questões financeiras do casal, em que as despesas sejam realizadas em conjunto, sem haver dependência econômica de um em relação ao outro (Ribeiro \& Ribeiro, 1995).

Em situações de dificuldades financeiras, o casal pode passar a ter conflitos por divergirem em opinião quanto ao uso do dinheiro, desencadeando inúmeras brigas e desentendimentos que, inclusive, nada tem a ver com a questão do dinheiro em si (Perguer, 2010). Hardie e Lucas (2010) realizaram um estudo nos Estados Unidos, com 1.625 casais coabitantes e 1.216 casais casados, com o objetivo de investigar a relação entre os fatores econômicos e a qualidade conjugal em jovens casais, comparando essa relação entre casados e coabitantes. Esse estudo apontou que as dificuldades financeiras estavam fortemente associadas com os conflitos conjugais tanto em casais coabitantes quanto casados. Segundo Schramm, Marshall, Harris e Lee (2005), essa é uma realidade previsível, porque as decisões ligadas às des- pesas ocupam um dos lugares de destaque na lista de preocupações dos casais, além de ser a principal fonte de conflitos. Isso ocorre especialmente quando um deles sente que o outro tem maior influência nas decisões (Kirchler, Rodler, Holzl, \& Meier, 2001; Razera, Cenci, \& Falcke, 2015).

Percebe-se que o dinheiro costuma ser um motivo de brigas constantes entre o casal, mas, segundo Cezar-Ferreira (2007), esses conflitos independem do montante de dinheiro que o casal possui, bem como do nível socioeconômico ou de escolaridade de ambos. A dificuldade parece situar-se na maneira como essas brigas acontecem, já que o dinheiro pode ser um dispositivo de ataque dos cônjuges e resultar em ressentimentos entre o casal. Garbin, Cenci e Luz (2015) ressaltam que equilibrar demandas afetivas e financeiras individuais e conjugais é uma tarefa complexa, que exige diálogo e respeito entre as partes.

Entretanto, é importante salientar que as questões financeiras não podem ser avaliadas separadamente do contexto como um todo, pois, como Gottman (1998) e Féres-Carneiro, Ziviani e Magalhães (2011) mencionam, a dificuldade financeira não é um fator que, por si só, influencia negativamente o casamento. Também não é capaz de predizer a sua manutenção ou dissolução (Paraguassú, 2005). É uma avaliação subjetiva do sujeito, e não a medida objetiva da situação financeira, que afeta o humor e a interação dele com os outros (Kinnunen \& Feldt, 2004; Price, Choi, \& Vinokur, 2002), podendo refletir na sua relação conjugal.

Em pesquisa realizada por Papp, Cummings e Goeke-Morey (2009), com 100 maridos e 100 esposas, a maioria caucasianos, com a média de 12 anos de casamento, cujo objetivo foi investigar se o dinheiro estaria associado aos conflitos conjugais, observou-se que os conflitos monetários eram os mais problemáticos e recorrentes, permanecendo por longos períodos sem solução. Esse dado é corroborado por Cenci (2016) que, em estudo com 123 casais heterossexuais gaúchos, destacou que o dinheiro é um dos temas de conflitos com maior dificuldade de resolução na conjugalidade.

Entende-se que os problemas em relação às finanças geralmente dizem respeito à forma como os cônjuges querem gerenciá-las (Cezar-Ferreira, 2007). As questões financeiras em um relacionamento são bastante complexas, pois enquanto o bem-estar econômico pode prover aspectos positivos na qualidade conjugal, por outro lado as dificuldades podem instigar o conflito (Hardie \& Lucas, 2010).

Em 1989, Pahl formulou quatro categorias de gerenciamento do dinheiro que são as mais comumente vistas entre os casais. Essas quatro categorias seriam: 1) Sistema de gerenciamento total dos gastos: todo o ganho salarial é gerenciado por uma única pessoa, segundo o autor, geralmente a esposa. Essa pessoa gerencia todas as despesas da casa, 


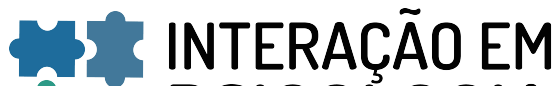 ET PSICOLOGIA}

exceto os gastos pessoais do parceiro. Ele revela, ainda, que quando o homem é quem gerencia o dinheiro, ele pode fazer com que a mulher não tenha acesso a ele sem sua permissão; 2) Sistema de gerenciamento por mesada ou pensão: um dos cônjuges é o principal provedor financeiro, fornecendo um valor para as despesas da casa e mantendo um valor não revelado para outros gastos, inclusive pessoais; 3) Sistema de gestão compartilhada: ambos os cônjuges têm acesso ao dinheiro e ambos têm um papel ativo na tomada de decisões financeiras e 4) Sistema de gestão independente: cada cônjuge tem o controle individual sobre sua renda e compromissos individuais com as despesas. Nesse sistema, nenhum dos cônjuges tem acesso ao dinheiro do outro.

No gerenciamento financeiro do casal, também se pode analisar o quanto ambos conseguem manter seus gastos sem maiores dívidas. Tanto esse é um fator importante que um estudo (Dew, 2008) realizado com 1.078 casais, entre eles europeus, africanos e hispânicos, com o objetivo de investigar a relação entre as dívidas e a satisfação conjugal em casais recém-casados, sugeriu que as dívidas assumidas pelo casal fazem com que a satisfação conjugal torne-se um desafio constante. Nesse estudo, entendeu-se que tanto as mudanças nas expectativas relacionadas ao casamento quanto as dívidas assumidas pelo casal estão, ambas, associadas ao declínio da satisfação conjugal.

Todos os aspectos mencionados pela literatura e pelos estudos encontrados mostram o quanto a relação conjugal está permeada por diversos fatores que não agem sozinhos, mas estão interligados. Nesse sentido, não só o dinheiro, mas a forma como os casais o manejam também pode se refletir na qualidade conjugal. Assim, este artigo foi proposto com o intuito de investigar a relação entre a qualidade conjugal e o manejo do dinheiro pelo casal. Mais especificamente, mensurar a qualidade conjugal dos casais participantes e caracterizar como eles lidam com as finanças do casal. Além disso, buscou-se verificar se existem diferenças na qualidade conjugal e no manejo do dinheiro pelo casal considerando as variáveis sociodemográficas (sexo, idade, tempo de relacionamento, renda, nível de instrução, situação conjugal e de trabalho).

\section{MÉTODO}

\section{DELINEAMENTO}

Trata-se de uma pesquisa quantitativa, com delineamento correlacional, para que se pudesse investigar a relação entre as variáveis estudadas.

\section{PARTICIPANTES}

A amostra dessa pesquisa foi composta por 143 casais com idade entre 19 e 81 anos ( $m=41,23$; dp = 12,77), moradores da região Metropolitana de Porto alegre. Desses casais, $60,6 \%$ eram casados oficialmente e $39,4 \%$ moravam juntos. 0 tempo médio de relacionamento desses casais foi de 15,7 anos ( $d p=12,1)$ e a idade média com que se casaram foi de 26,5 anos ( $d p=7,3$ ). Como pode ser observado na Tabela 1, a maioria dos participantes era casada oficialmente $(60,6 \%)$, possuía filhos $(68,1 \%)$, era da religião Católica $(67,3 \%)$ e exercia atividade remunerada $(86,1 \%)$.

\section{Tabela 1. Caracterização dos participantes}

\begin{tabular}{|c|c|c|}
\hline $\begin{array}{l}\text { Tempo de } \\
\text { relacionamento }\end{array}$ & & $\begin{array}{l}M=15,7 \\
D P=12,1\end{array}$ \\
\hline Idade com que & & $M=26,5$ \\
\hline casou & & $\mathrm{DP}=7,3$ \\
\hline Situação & Casados oficialmente & $60,6 \%$ \\
\hline conjugal & Morando juntos & $39,4 \%$ \\
\hline \multirow[t]{2}{*}{ Filhos } & Tem & $68,1 \%$ \\
\hline & Não tem & $31,9 \%$ \\
\hline \multirow[t]{5}{*}{ Escolaridade } & Sem instrução formal & $0,8 \%$ \\
\hline & Fundamental & $8,7 \%$ \\
\hline & Médio & $44,2 \%$ \\
\hline & Superior & $22,3 \%$ \\
\hline & Pós graduação & $24,2 \%$ \\
\hline \multirow[t]{6}{*}{ Religião } & Católica & $67,3 \%$ \\
\hline & Evangélico & $9,7 \%$ \\
\hline & Espírita & $7,2 \%$ \\
\hline & Protestante & $4,3 \%$ \\
\hline & Sem religião & $6,8 \%$ \\
\hline & Outra & $4,7 \%$ \\
\hline \multirow[t]{2}{*}{ Trabalho } & Exerce atividade remunerada & $83,9 \%$ \\
\hline & $\begin{array}{l}\text { Não exerce atividade } \\
\text { remunerada }\end{array}$ & $16,1 \%$ \\
\hline
\end{tabular}

Quanto à situação de trabalho, 53,8\% possuíam vínculo como empregados, $30,1 \%$ eram autônomos, $8,6 \%$ eram aposentados ou pensionistas, $3,9 \%$ exerciam atividade no lar, $2,2 \%$ eram estudantes e $1,4 \%$ estavam desempregados. A média de renda pessoal dos homens (R\$ 4.195,96) foi significativamente $(t=-2,572 ; p=0,011)$ maior do que a das mulheres $(\mathrm{R} \$ 2.828,74)$.

\section{INSTRUMENTOS}

Para essa pesquisa foram utilizados como instrumentos um questionário de dados sociodemográficos, a Escala de 


\section{WIIITERACÃO EM ET. PSICOLOGIA}

Ajustamento Diádico (Dyadic Adjustment Scale - DAS, Spanier, 1976), uma escala que avalia a qualidade conjugal (Golombok Rust Inventory of Marital State - GRIMS, Rust, Bennun, Crowe, \& Golombok, 1990) e um questionário sobre o manejo do dinheiro.

O questionário de dados sociodemográficos coletou informações como idade, escolaridade, situação conjugal, filhos, tempo de casamento, religião, situação ocupacional e renda, buscando caracterizar a amostra do estudo.

A DAS (Spanier, 1976) é uma escala utilizada para investigar o ajustamento diádico do casal, sendo avaliada em quatro dimensões: consenso, satisfação, coesão e expressão de afeto. É composta por 32 itens, sendo 30 deles em escala $\mathrm{Li}$ kert, com cinco a sete opções de respostas, que variam de "sempre em desacordo" a "sempre em acordo" ou desde "sempre" a "nunca", sendo que a maioria dos itens contém seis opções de respostas. Dois itens possuem apenas duas opções de resposta, "sim" ou "não". Em um estudo brasileiro (Hernandez, 2008), o Alfa de Cronbach geral da DAS foi de 0,93 , confirmando sua consistência interna para aplicação em população brasileira.

O GRIMS é um inventário que se propõe a avaliar a qualidade do relacionamento conjugal através de cinco dimensões consideradas importantes, como a satisfação, a comunicação, os interesses compartilhados, a confiança e o respeito. Ele é composto por 28 itens dispostos em escala Likert de quatro pontos, sendo elas "discordo fortemente", "discordo", "concordo" e "concordo fortemente". Esse inventário indica que quanto maior os escores atingidos, mais severos são os problemas na relação conjugal. O GRIMS foi traduzido e adaptado para o Brasil por Falcke (2003), tendo obtido Alfa de Cronbach de 0,91.

Para avaliar o manejo do dinheiro pelo casal, foi utilizado um questionário (Harth, 2013) com versão masculina e feminina. Este questionário possui um total de 18 questões, que avaliam três dimensões acerca do manejo do dinheiro pelo casal - a dimensão descritiva da situação financeira do casal, com 11 questões, sendo 10 delas com respostas "sim" ou "não' e uma questão de enumerar prioridades de gastos de 1 a 9; a dimensão da infidelidade conjugal, com seis questões, sendo quatro em escala Likert de quatro pontos cada uma (duas delas com resposta de "nunca" a "frequentemente" e as outras duas com respostas de "discordo completamente" a "concordo completamente") e duas questões de verdadeiro ou falso; e a dimensão das categorias de gerenciamento do dinheiro, com uma questão na qual os participantes devem escolher uma dentre quatro alternativas, considerando aquela que melhor descreve a forma como eles manejam o dinheiro do casal. 0 Alfa de Cronbach obtido ao final deste estudo foi de 0,895 , indicando a confiabilidade do instrumento.

\section{PROCEDIMENTOS DE COLETA DE DADOS}

Após aprovação no Comitê de Ética da Unisinos (parecer número 11/129), os participantes foram contatados por conveniência. Em seguida, foi feito um rapport explicando os objetivos da pesquisa, sendo solicitado aos participantes que assinassem o Termo de Consentimento Livre e Esclarecido (TCLE), garantindo que estavam cientes de sua participação nessa pesquisa. 0 questionário foi aplicado aos cônjuges separadamente, de forma que um não soubesse das respostas do outro, em local escolhido pelo casal.

\section{ANÁLISE DOS DADOS}

Os dados foram trabalhados estatisticamente através de análises descritivas e inferenciais. A avaliação da associação entre a qualidade conjugal e o manejo do dinheiro pelo casal foi feita através de correlação de Pearson. Comparações entre grupos foram realizadas através do teste $t$ de Student ou de análise de variância.

\section{RESULTADOS}

\section{MANEJO DO DINHEIRO PELO CASAL}

A maioria dos participantes $(55,4 \%)$ referiu que ambos os cônjuges contribuem nas despesas da casa, sendo que $86,7 \%$ consideraram que a renda familiar deles é suficiente para viverem. Os homens apareceram como aqueles que contribuem mais nas despesas da casa, ainda que essa diferença seja muito pequena $(50,4 \%$ para os homens e $49,6 \%$ para as mulheres), o que talvez justifique o fato da maioria (90,9\%) ter mencionado que o(a) companheiro(a) não deveria contribuir mais do que já contribuía nas despesas da casa.

Um percentual de $86 \%$ dos participantes disse concordar com a maioria dos gastos do(a) companheiro(a), ainda que $20,9 \%$ destes tenham relatado haver brigas quando ocorre um gasto indevido por parte do(a) companheiro(a). Quanto ao controle do dinheiro do casal, $67,5 \%$ dos participantes mencionaram que ambos são responsáveis pelas decisões financeiras. Dos 32,5\% que referiram decisões independentes, em $17,3 \%$ dos casos a decisão final é da mulher e em $15,2 \%$ a decisão final é do homem. Grande parte dos participantes $(83,5 \%)$ alegou que outras pessoas ajudam na renda deles (pais, sogros, avós e filhos).

Quanto às prioridades de gastos dos participantes, 50,2\% mencionaram a alimentação como a primeira prioridade, seguido de $33,2 \%$ que relataram as despesas da casa (aluguel, condomínio, água e luz) como segunda prioridade, 26,9\% com a saúde como terceira prioridade, o transporte $(24,3 \%)$ e o vestuário $(21,6 \%)$ como quinta prioridade, o lazer (televisão, 


\section{MI* INTERACÃO EM LF PSICOLOGIA}

internet, etc.) em sexta prioridade com $25,2 \%$, os interesses pessoais $(26,1 \%)$ e os investimentos $(31,3 \%)$ como oitava prioridade e, por fim, $61,5 \%$ citaram a opção "outros" como nona prioridade, indicando que todas as opções de gastos já haviam sido contempladas nas questões anteriores.

A maioria dos participantes (57,5\%) afirmou que já juntou suas finanças com seu(sua) companheiro(a) alguma vez. Os tipos de finanças seriam a conta corrente com 18,2\%, cartão de crédito com 15,5\%, poupança com $14,2 \%$ e dinheiro com $6,1 \%$ dos participantes. Um total de $35,8 \%$ dos participantes menciona que já juntou as finanças em mais de uma dessas opções e 10,1\% dizem já terem juntado outro tipo de finança, além das mencionadas, como bens, investimentos e dívidas. Percebe-se que mesmo que $42,5 \%$ dos participantes nunca tenha juntado suas finanças com seu(sua) parceiro(a), 79,3\% destes planejam os gastos financeiros em conjunto.

Tabela 2. Percentual de respostas sobre indicativos de infidelidade financeira

\begin{tabular}{lcccc}
\hline & Nunca & Raramente & $\begin{array}{c}\text { Às } \\
\text { vezes }\end{array}$ & Frequentemente \\
\hline Escondi dinheiro do meu companheiro & 77,0 & 14,7 & 7,9 & 0,4 \\
Escondi um pequeno gasto do meu companheiro & 58,1 & 28,2 & 12,3 & 1,4 \\
Escondi um grande gasto do meu companheiro & 88,1 & 8,3 & 3,2 & 0,4 \\
Escondi um extrato bancário do meu companheiro & 84,8 & 10,9 & 3,6 & 0,7 \\
Escondi uma conta bancária do meu companheiro & 92,8 & 4,3 & 2,9 & 0 \\
Menti ao meu companheiro sobre algo relacionado às finanças & 77,5 & 16,7 & 5,1 & 0,7 \\
Menti ao meu companheiro sobre uma dívida que eu devia & 81,9 & 13,0 & 2,9 & 2,2 \\
Menti ao meu companheiro sobre quanto dinheiro eu ganho/ ganhava & 89,5 & 7,6 & 2,2 & 0,8 \\
Peguei dinheiro do meu companheiro sem ele saber & 93,5 & 5,0 & 0,4 & 1,1 \\
\hline
\end{tabular}

Considerando as variáveis sociodemográficas, observouse que as situações de infidelidade financeira cometidas pelo sujeito se correlacionaram com a renda $(r=-0,131 ; p=0,045)$. Não houve diferenças nas situações de infidelidade considerando o sexo $(p=0,454)$, a idade $(p=0,258)$, a escolaridade $(p=0,110)$, a situação conjugal $(p=0,863)$ e de trabalho $(p=$ $0,661)$ e o tempo de relacionamento $(p=0,330)$.

A Tabela 3 apresenta os dados a respeito da percepção dos participantes sobre as atitudes dos cônjuges.

Com os resultados da Tabela 3, percebe-se que os participantes acreditam que seus companheiros, assim como eles mesmos, em sua maioria, nunca cometeram nenhuma situação de infidelidade financeira. Um total de $91,9 \%$ dos participantes diz que seu(sua) companheiro(a) nunca pegou
Os participantes também responderam questões sobre situações de infidelidade financeira cometida tanto por eles, quanto por seus(suas) companheiros(as). A Tabela 2 apresenta os dados relacionados à infidelidade financeira cometida por eles, a partir do percentual de respostas dos participantes.

Conforme a tabela acima, pode-se pontuar que a grande maioria dos participantes nunca cometeu qualquer uma das situações de infidelidade financeira mencionadas, sendo que $93,5 \%$ afirmaram nunca terem pegado dinheiro do(a) parceiro(a) sem que ele(a) soubesse. Dentre os participantes que já cometeram alguma infidelidade financeira, a maioria refere que foram raras as vezes em que isso aconteceu, sendo que a situação mais comum foi esconder um pequeno gasto do(a) parceiro(a), com $28,2 \%$. 


\section{H NTERAC̄öEM PSICOLOGIA}

Tabela 3. Percentual de respostas sobre indicativos de infidelidade financeira cometidos pelo(a) companheiro(a)

\begin{tabular}{|c|c|c|c|c|}
\hline & Nunca & Raramente & $\begin{array}{c}\text { Às } \\
\text { vezes }\end{array}$ & Frequentemente \\
\hline Meu companheiro escondeu dinheiro de mim & 80,7 & 11,7 & 6,2 & 1,4 \\
\hline Meu companheiro escondeu um pequeno gasto de mim & 61,2 & 23,8 & 12,5 & 2,5 \\
\hline Meu companheiro escondeu um grande gasto de mim & 86,2 & 8,4 & 3,6 & 1,8 \\
\hline Meu companheiro escondeu um extrato bancário de mim & 88,0 & 7,3 & 2,9 & 1,8 \\
\hline Meu companheiro escondeu uma conta bancária de mim & 92,6 & 4,1 & 2,2 & 1,1 \\
\hline Meu companheiro mentiu sobre algo relacionado às finanças & 82,0 & 11,4 & 5,5 & 1,1 \\
\hline Meu companheiro mentiu sobre uma dívida que ele devia & 87,5 & 7,0 & 3,3 & 2,2 \\
\hline Meu companheiro mentiu sobre quanto dinheiro ele ganha/ ganhava & 91,2 & 4,8 & 2,6 & 1,4 \\
\hline Meu companheiro pegou dinheiro meu sem eu saber & 91,9 & 5,5 & 1,5 & 1,1 \\
\hline
\end{tabular}

amento financeiro feito por eles. A Figura 1 demonstra os resultados obtidos.

Conforme as categorias de gerenciamento do dinheiro estipuladas por Pahl (1989), a maioria dos participantes (58\%) mencionaram que ambos os cônjuges gerenciam o dinheiro do casal, $25 \%$ dos participantes relataram que mantêm suas finanças separadas, da mesma forma como assumem compromissos individuais com as despesas da casa, $13 \%$ afirmaram que apenas um dos cônjuges é responsável pelo gerenciamento do dinheiro do casal e $4 \%$ disseram que um dos cônjuges destina parte do seu ganho salarial para o(a) companheiro(a) gerenciar as despesas domésticas.

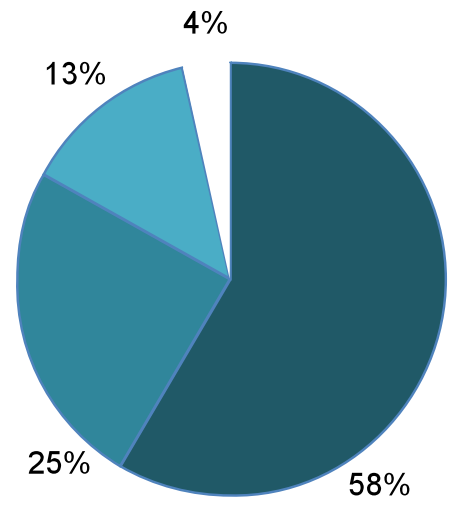

- Sistema de gestão compartilhada do dinheiro

- Sistema de gestão independente do dinheiro

Sistema de gerenciamento total dos gastos

Sistema de gerenciamento por mesada ou pensão

Figura 1. Manejo do dinheiro pelo casal

\section{QUALIDADE CONJUGAL}

A Figura 2 apresenta a distribuição dos casais com relação aos níveis de qualidade conjugal obtidos através do GRIMS:
Problemas muito severos

Problemas severos 3.7

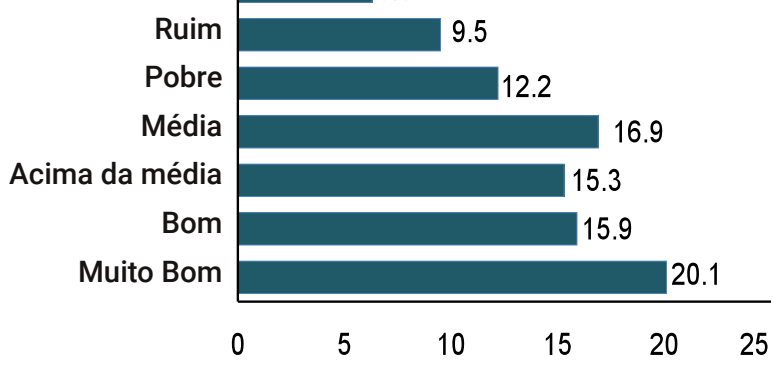

Figura 2. Porcentagem de distribuição pelos níveis de qualidade conjugal (GRIMS)

Observa-se que a maioria dos casais obteve bons níveis de qualidade conjugal, situando-se na média ou acima (58,3\%). Do total, $12,2 \%$ apresentaram pobre qualidade conjugal, $9,5 \%$ ruim, $6,3 \%$ problemas severos no relacionamento e $3,7 \%$ problemas muito severos no relacionamento.

Observou-se que a qualidade conjugal não se diferenciou conforme o sexo $(p=0,719)$, a situação conjugal $(p=0,641)$, a idade $(p=0,429)$, o tempo de relacionamento $(p=0,103)$, a escolaridade $(p=0,257)$, a situação de trabalho $(p=0,344)$ e a renda $(p=0,597)$

Considerando os dados da DAS, confirmam-se os bons níveis de ajustamento conjugal, ao verificar-se que, em uma escala de zero a seis, em que o zero corresponde a sentir-se extremamente infeliz com o relacionamento e seis a extremamente feliz, a média dos participantes foi de 4,53. Além disso, a maioria dos participantes $(51,6 \%)$ relatou que raramente discute ou considera a possibilidade de se divorciar, separar ou terminar o relacionamento. Apenas 5,3\% dizem brigar frequentemente. 


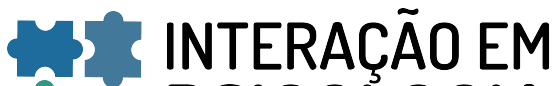 ET. PSICOLOGIA}

Um total de $82,9 \%$ dos participantes alegaram pensar na maior parte do tempo que as coisas com seu(sua) companheiro(a) estão indo bem, talvez pelo fato de $94,6 \%$ deles confiarem no seu(sua) parceiro(a) na maior parte do tempo. Ainda assim, 26,5\% dos participantes mencionaram que ocasionalmente se lamentam por seu casamento ou por estarem vivendo juntos e $51,9 \%$ disseram que ambos ocasionalmente perdem o controle nas discussões.

Considerando as dimensões de concordância ou discordância entre os cônjuges mensuradas pela DAS, em uma escala Likert de seis pontos em que um indica que o casal discorda sempre sobre o assunto e seis que o casal concorda sempre, verifica-se na Figura 3 que o manejo das finanças familiares aparece como o quarto fator de menor concordância, seguido apenas por convenções, lazer e tarefas domésticas.

Do total de participantes, $19,2 \%$ referiram discordar ocasionalmente sobre as finanças, $5,7 \%$ discordar frequentemente, $2,8 \%$ discordar quase sempre e $1,4 \%$ discordar sempre. Buscando associações com as variáveis sociodemográficas, observou-se que o grau de concordância entre os cônjuges no que se refere ao manejo das finanças, avaliado pela DAS, não se diferenciou conforme o sexo $(p=0,931)$, a situação conjugal $(p=0,721)$ e de trabalho $(p=0,749)$ e a escolaridade $(p=$ $0,608)$. Além disso, não se correlacionou com a idade $(p=$

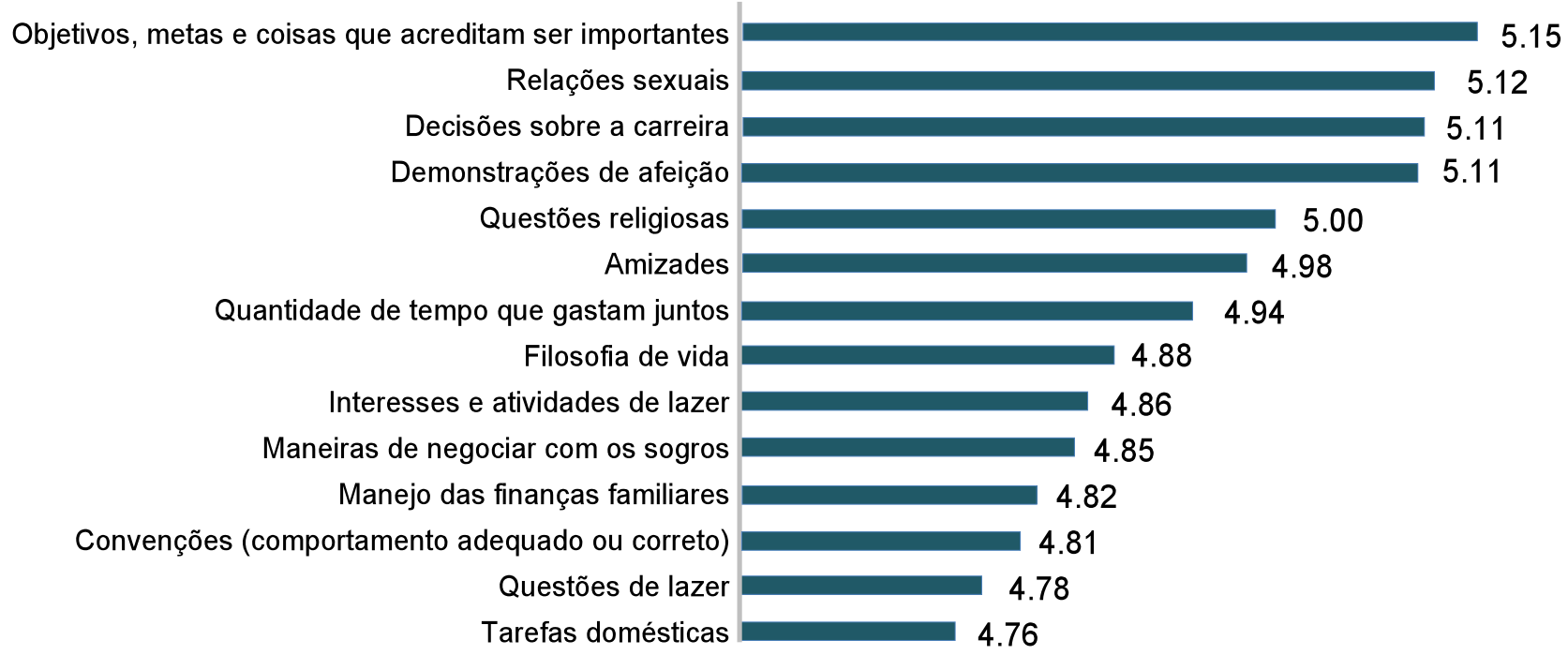

Figura 3. Médias de concordância entre os cônjuges

$0,469)$, com o tempo de relacionamento $(p=0,690)$ e com a renda $(p=0,941)$.

\section{CORRELAÇÃO MANEJO DO DINHEIRO X QUALIDADE CONJU- GAL}

Para avaliar a correlação entre as categorias de manejo do dinheiro e a qualidade conjugal, inicialmente, foi realizado um agrupamento das categorias, considerando que o sistema de gerenciamento por mesada ou pensão foi adotado por somente $4 \%$ dos casais participantes. Nesse sentido, como ele se refere a uma situação em que somente um dos cônjuges gerencia o dinheiro, optou-se por agrupá-lo com o sistema de gerenciamento total dos gastos, que também é exercido por somente um dos cônjuges. Sendo assim, definiram-se três formas de gerenciamento, conforme se pode observar na $\mathrm{Fi}$ gura 4.
Através de uma análise de variância, verificou-se que houve diferença significativa $(F=5,116 ; p=0,007)$ na qualidade conjugal considerando os três grupos conforme o manejo do dinheiro, sendo que o grupo com pior qualidade conjugal foi aquele em que um dos cônjuges controla individualmente as finanças do casal $(m=30,05)$, seguido pelos casais que lidam separadamente com as despesas da casa e o dinheiro do casal ( $m=29,80$ ) e com uma melhor qualidade conjugal aparece o grupo que maneja em conjunto $(m=24,19)$.

A mesma constatação ocorreu quanto ao nível de concordância ou discordância em relação ao dinheiro $(F=7,530 ; p=$ $0,001)$ e o grau de felicidade no relacionamento $(F=11,319 ; p$ $<0,001)$ mensurado pela DAS. Dessa análise observa-se que os casais que manejam o dinheiro em conjunto são aqueles que tiveram maior índice de concordância em relação ao destino do dinheiro $(m=5,11)$, quando comparados aos casais 


\section{WII INTERACÃO EM ET. PSICOLOGIA}

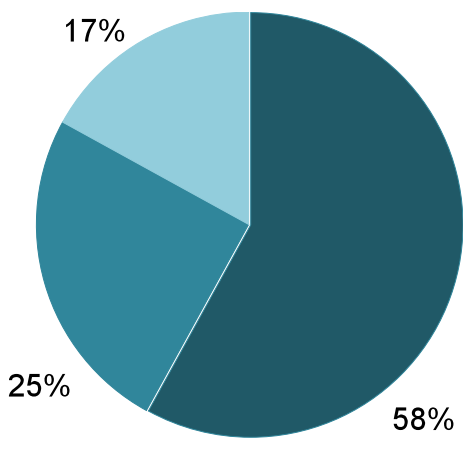

Manejo em conjunto

Manejo separado

Manejo por um dos cônjuges

Figura 4. Manejo do dinheiro pelo casal

em que um dos cônjuges decide sozinho $(m=4,50)$ e aos que lidam separadamente $(m=4,46)$. Na mesma direção, os que manejam em conjunto apresentaram maior grau de felicidade com o relacionamento $(m=4,92)$, quando comparados aos casais que gerenciam separadamente as finanças $(m=4,10)$ e aos casais nos quais um dos cônjuges gerencia o dinheiro do casal $(m=3,93)$.

\section{DISCUSSÃO}

Com os resultados obtidos nesse trabalho, observou-se, através do GRIMS, que a maioria dos casais ficou na média ou acima da média no quesito qualidade conjugal. Esse resultado é confirmado pela DAS, mostrando o bom ajustamento dos casais, de maneira geral. É interessante mencionar que, diferente do que se esperava, a qualidade conjugal dos participantes não se diferenciou em relação a cada uma das variáveis sociodemográficas, contrariando dados de estudos prévios que apontavam os homens como mais satisfeitos com seus relacionamentos conjugais (Féres-Carneiro, 1998).

Ainda que o manejo das finanças tenha aparecido como o $4^{\circ}$ fator de menor concordância entre os casais, observou-se que aqueles casais que lidam com o dinheiro em conjunto são os que obtiveram maior índice de concordância em relação às finanças, sendo, também, aqueles que apresentaram maior grau de felicidade com o relacionamento. Esses resultados nos possibilitam perceber, conforme já postulado por Hardie e Lucas (2010), que o bem-estar econômico, aqui apresentado na forma de concordância em relação às finanças, está associado a aspectos positivos na qualidade conjugal. Inclusive observou-se que, para os participantes desse estudo, o grau de concordância em relação às finanças não se diferenciou quando analisadas as demais variáveis sociodemográficas.

Alguns autores (Cezar-Ferreira, 2007; Papp, Cummings \&
Goeke-Morey, 2009; Razera, Cenci, \& Falcke, 2015) mencionam que a qualidade conjugal pode estar associada, não com o nível socioeconômico dos casais, mas com a forma que eles manejam esse dinheiro. Entretanto, nesse estudo observou-se correlação entre a renda e situações de infidelidade financeira, indicando que quanto maior a renda, menos situações de infidelidade financeira foram cometidas. Esse dado nos permite inferir que, nesse estudo, tanto o manejo como o status econômico desses casais esteve associado com maior qualidade conjugal e menor presença de infidelidade financeira. Nesse sentido, pode-se pensar que o nível socioeconômico atue como fator complementar ao tipo de manejo que os casais fazem, diferente do que foi mencionado anteriormente por Carlson, McLanahan e England (2004) e Sharlin, Kaslow e Hammerschmidt (2000), necessitando novos estudos para confirmar essa relação.

Observou-se que o grupo que maneja o dinheiro através de um único membro do casal foi o que apresentou pior qualidade conjugal, possivelmente pelo dinheiro constituir-se, no contexto desses casais, em um dispositivo de poder, podendo levá-los a uma maior dificuldade de abrir mão do controle em favor da relação (Silveira, 2007). Ainda pode-se pensar que os conflitos entre esses casais com pior qualidade conjugal, em que o dinheiro é controlado por um dos cônjuges, estejam relacionados à possibilidade de discórdias quando um deles sente que o outro tem maior influência nas decisões ligadas ao dinheiro, conforme achados da pesquisa de Kirchler, Rodler, Holzl e Meier (2001).

Também observamos que a maioria dos casais contribuíam igualmente nas despesas da casa. Esse resultado nos faz pensar que os casais têm reivindicado maior igualdade financeira, de forma que ambos se responsabilizem pelas despesas em conjunto. Essa reivindicação já foi relatada por Ribeiro e Ribeiro (1995), inclusive citando que os casais também preferem que não haja dependência financeira de um em relação ao outro. É interessante ressaltar que a maioria dos participantes já juntou suas finanças e mesmo aqueles que nunca o fizeram, planejam todos os gastos em conjunto, levando a entender que eles conseguem manter sua independência, conciliando as dimensões de individualidade e conjugalidade (Féres-Carneiro, 1998).

Os dados deste estudo permitem concluir que a dificuldade financeira não é algo que por si só possa influenciar negativamente o casamento, da mesma forma que não seria capaz de predizer se esse casamento permanecerá ou se dissolverá (Paraguassú, 2005), mas é um fenômeno complexo que impacta o cotidiano conjugal, estando o sistema de gerenciamento financeiro diretamente relacionado à qualidade conjugal. Nesse sentido, é a forma como o casal consegue lidar com a situação que pode afetar o humor e a interação de 


\section{MI* INTERACÃO EM LF PSICOLOGIA}

um com o outro (Kinnunen \& Feldt, 2004; Price, Choi, \& Vinokur, 2002), afetando, enfim, a relação conjugal.

\section{CONSIDERAÇÕES FINAIS}

De maneira geral, neste estudo percebe-se que os resultados se apresentam em conformidade com os postulados anteriores em relação ao tema proposto. Alguns autores já vinham relatando a ideia de relação entre qualidade conjugal e o manejo financeiro dos casais e esse estudo permite reafirmar essa colocação, pois verificou-se que a qualidade conjugal esteve fortemente associada ao manejo do dinheiro pelos casais participantes. Inclusive, neste estudo, os casais que manejam o dinheiro conjuntamente foram aqueles que obtiveram melhor índice de qualidade conjugal, maior concordância em relação às finanças e maior grau de felicidade no relacionamento conjugal.

Neste trabalho não medimos o nível de endividamento dos casais, mas foi identificada correlação negativa entre a renda e situações de infidelidade financeira, como esconder uma pequena dívida do(a) companheiro(a). Diante de situações como essa, alguns casais optaram por manter suas finanças separadas. Essa situação poderia sugerir que as dívidas assumidas pelo casal fazem com que a satisfação conjugal torne-se um desafio constante, conforme já disse Dew (2008). Por fim, uma sugestão para um próximo estudo, seria avaliar a relação entre o grau de endividamento do casal e a qualidade conjugal, com o objetivo de investigar se as situações de endividamento por parte dos cônjuges, em menor ou maior grau, estariam associadas à menor ou maior qualidade conjugal. Estudos com essa finalidade poderiam contribuir para o entendimento da dinâmica de manejo do dinheiro e sua relação com a qualidade conjugal.

\section{CONTRIBUIÇÃO DE CADA AUTOR}

Redação, revisão e edição feitas por J.H. A analise de dados e supervisão foram feitas por D.F.

\section{DECLARAÇÃO DE CONFLITOS DE INTERESSES}

Os autores declararam que não há conflitos de interesses no presente artigo.

\section{REFERÊNCIAS}

Carlson, M., McLanahan, S., \& England, P. (2004). Union formation in fragile families. Demography, 41, 237-261. http://dx.doi.org/10.1353/dem.2004.0012
Cenci, C. M. B. (2016) Relações entre significado e manejo do dinheiro, ajustamento diádico e conflito conjugal. Tese de Doutorado. Psicologia, PUCRS.

Cezar-Ferreira, V. A. M. (2007). Família, separação e mediação: uma visão psicojurídica. São Paulo: Editora Método.

Dew, J. (2008). Debt change and marital satisfaction change in recently married couples. Family Relations, 57, 60-71. http://dx.doi.org/10.1111/j.1741-3729.2007.00483.x

Falcke, D. (2003). Águas passadas não movem moinhos? As experiências na família de origem como preditoras da qualidade do relacionamento conjugal. Tese de doutorado. Psicologia, PUCRS.

Féres-Carneiro, T. (1998). Casamento contemporâneo: O difícil convívio da individualidade com a conjugalidade. Psicologia: Reflexão e Crítica, 11(2), 379-394.

Féres-Carneiro, T., Ziviani, C., \& Magalhães, A. S. (2011). Arranjos amorosos contemporâneos: Sexualidade, fidelidade e dinheiro na vivência da conjugalidade. In: T. Féres-Carneiro. (org.). Casal e família: Conjugalidade, parentalidade e psicoterapia. (pp 43-60). São Paulo: Casa do Psicólogo.

Garbin, A., Cenci, C. M. B., \& Luz, S. K. (2015). Money and conjugality. Revista de Psicologia da IMED, 7(1), 72-78.

Gottman, J. M. (1998). Casamentos: Por que alguns dão certo e outros não. São Paulo: Editora Objetiva.

Hardie, J. H. \& Lucas, A. (2010). Economic factors and relationship quality among young couples: Comparing cohabitation and marriage. Journal of Marriage and Family, 72, $1141-1154$. http://dx.doi.org/10.1111/j.17413737.2010.00755.x

Harth, J. (2013). O manejo do dinheiro pelo casal e suas implicações na qualidade conjugal. Dissertação de Mestrado. Psicologia, Unisinos.

Hernandez, J. A. E. (2008). Avaliação estrutural da escala de ajustamento diádico. Psicologia em Estudo (Maringá), 13(3), 593-601.

Kinnunen, U., \& Feldt, T. (2004). Economic stress and marital adjustment among couples: Analyses at the dyadic level. European Journal of Social Psychology, 34, 519-532. http://dx.doi.org/10.1002/ejsp.213

Kirchler, E., Rodler, C., Holzl, E., \& Meier, K. (2001). Conflict and decision making in close relationships. Hove: The Psychology Press.

Magalhães, A. S. (2003). Transmutando a subjetividade na conjugalidade. In: T. Féres-Carneiro. (org.). Família e casal: Arranjos e demandas contemporâneas. (pp 225-245). Rio de Janeiro/São Paulo: Editora PUC-Rio/Loyola.

Mosmann, C., Wagner, A., \& Féres-Carneiro, T. (2006). Qualidade conjugal: Mapeando conceitos. Paidéia, 16(35), 315325. 


\section{- H* INTERACÃO EM LF PSICOLOGIA}

Pahl, J. (1989). Money and marriage. London: MacMillan.

Papp, L. M., Cummings, E. M., \& Goeke-Morey, M. C. (2009). For richer, for poorer: Money as a topic of marital conflict in the home. Family Relations, 58, 91-103. http://dx.doi.org/10.1111/j.1741-3729.2008.00537.x

Paraguassú, L. A. (2005). Influências econômicas na manutenção do relacionamento conjugal: Um estudo exploratório. Salvador: Faculdade Ruy Barbosa.

Perguer, N. K. (2010). Variáveis que devem ser consideradas na avaliação da qualidade do relacionamento conjugal. Revista Perspectivas, 1(2), 116-129.

Price, R. H., Choi, J. N., \& Vinokur, A. D. (2002). Links in the chain of adversity following job loss: How financial stress and loss of personal control lead to depression, impaired functioning, and poor health. Journal of Occupational Health Psychology, 7, 302-312. http://dx.doi.org/10.1037/1076-8998.7.4.302

Razera, J., Cenci, C. M., \& Falcke, D. (2015). Manejo de dinheiro: possíveis relações com o ajustamento e a violência em casais. Perspectivas em Psicologia, 19(2), 3-17.

Ribeiro, I., \& Ribeiro, A. C. T. (1995). Família em processos contemporâneos: Inovações culturais na sociedade brasileira. São Paulo: Loyola.

Ricotta, L. C. A. (2002). O vínculo amoroso: A trajetória da vida afetiva. ( $4^{\mathrm{a}}$ ed.) São Paulo: Editora Ágora.

Rust, J., Bennun, I., Crowe, M., \& Golombok S. (1990). The GRIMS. A psychometric instrument for the assessment of marital discord. Journal of Family Therapy, 12(1), 45-57. http://dx.doi.org/10.1046/j..1990.00369.x

Sharlin, A. S., Kaslow, F., \& Hammerschmidt, H. (2000). Together through thick and thin: A multinational picture of long-term marriages. Nova York: The Haworth Clinical Practice Press.
Schramm, D. G., Marshall, J. P., Harris, V. W., \& Lee, T. R. (2005). After "I Do": The newlywed transition. Marriage and Family Review, 38, 45-67. http://dx.doi.org/10.1300/J002v38n01_05

Silveira, T. M. (2007). O papel da criatividade nas relações conjugais: os limites do "eu" e os limites do "nós". Revista IGT na Rede, 4(7), 199-207.

Spanier, G. B. (1976). Measuring Dyadic Adjustment: New Scales for Assessing the Quality of Marriage and Similar Dyads. Journal of Marriage and The Family, 38(1), 15-26. http://dx.doi.org/10.2307/350547

Sweeney, M. (2002). Two decades of family change: The shifting economic foundations of marriage. American Sociological Review, 67, 132-147.

Teykal, C. M., \& Rocha-Coutinho, M. L. (2007). O homem atual e a inserção da mulher no mercado de trabalho. Psicologia (PUCRS), 38(3), 262-268.

VanLaningham, J., Johnson, D. R., \& Amato, P. (2001). Marital happiness, marital duration, and the u-shaped curve: Evidence from a fivewave panel study. Social Forces, 79, 1313-1341. http://dx.doi.org/10.1353/sof.2001.0055

Whitaker, A. (1990). Dançando com a família. Porto Alegre: Artes Médicas. 